\title{
LAS PASIONES Y LA VIDA MORAL: UNA VALORACIÓN DE LA ORIGINALIDAD DE SANTO TOMÁS*
}

Paul Gondreau**

\section{La Orestíada, antigua trilogía de} tragedias griegas, narra la historia de cómo el joven Orestes, después de vengar el asesinato de su padre matando a la homicida, su propia madre, debe huir de la persecución implacable de las terribles Furias. Estas últimas son las arcaicas diosas preolímpicas de la tierra, que vengan el asesinato de familiares. Finalmente, la diosa olímpica Atenea convence a las Furias de suspender, de manera momentánea, la persecución de la venganza de sangre y permitir, así, el juicio de un jurado que determine el destino de Orestes. Durante éste, las Furias, no sin razón, establecen sus motivos para fallar un castigo justo. Después de una apretada votación, resultado de un jurado vacilante, Atenea,

* Traducción de Mauricio López Noriega, con la colaboración de Cristina Morales A. (agradezco la revisión que gentilmente realizó el doctor Jaime Ruiz de Santiago). Ciertas secciones de este artículo han aparecido en otro ensayo, titulado "Humanizing the Emotions through Moral Virtue", el cual será publicado como parte de un proyecto mayor, patrocinado por el Instituto de Ciencias del Comportamiento (Institute for the Psychological Sciences, Arlington, Virginia). Una versión anterior de este texto fue leída como conferencia, en honor del octogésimo aniversario de fr. Servais Pinckaers, O. P., en octubre del 2005, en la Universidad de Friburgo, Suiza.

** Sacrae Theologiae Doctor, Profesor asociado de Teología, Providence College, Rhode Island. 
convencida de que la venganza de sangre conduce a una carnicería interminable, interviene e inclina la votación en forma favorable para Orestes, obteniendo su absolución como resultado.

Al señalar que la cerrada votación legitima los argumentos de las Furias, Atenea consigue ofrecerles un lugar, aunque subordinado, entre los Olímpicos, desde el cual no actuarán ya como diosas de la venganza, sino como protectoras de los lazos de sangre. Las Furias aceptan y se transforman en Euménides, en griego 'las amistosas'. Esto significa que toman un sitio como diosas de la tierra, que subordinan sus deseos instintivos inferiores por la venganza de sangre al sabio juicio de los dioses mayores, como Atenea. Moradoras celestes de la cima del monte Olimpo, estas encumbradas diosas siguen ahora la guía de la razón y de la sabiduría iluminada.

Pienso que, entre las muchas lecciones que se pueden espigar de esta antigua tragedia griega, escrita por el famoso trágico Esquilo, supremo entre ellos, se encuentra la invaluable comprensión que muestra sobre la naturaleza de la emoción humana y de su relación con la razón. Los impulsos instintivos inferiores, las emociones, ejemplificadas en la Orestíada por el deseo del justo castigo por parte de las Furias, diosas de la tierra, no son malas en sí mismas y podrían ser por completo legítimas. Por esta razón, no deben ser erradicadas de la vida humana. Movimientos de los apetitos inferiores, las emociones juegan un papel integral, y esencial, en nuestras vidas, de manera paralela a la forma en que las Furias, una vez transformadas en gentiles Euménides, comenzarán a jugar un papel integral y esencial en el panteón olímpico, como protectoras de los lazos de sangre. Pero, dado que las emociones pertenecen a la dimensión impulsiva inferior de la persona humana, se encuentran por naturaleza subordinadas a nuestras facultades superiores; y han de estarlo para servir al papel rector de la razón humana, nuestra potencia cognitiva superior, representada en la Orestíada por Atenea y los dioses olímpicos. El papel de la razón, como lo entiende Esquilo, es integrar armoniosamente las emociones, los impulsos inferiores a la vida humana, de forma balanceada, sin 
suprimirlas por completo, pero sin otorgarles señorío sobre nuestras acciones.

Esquilo nos brinda una visión de la emoción humana y de su relación con nuestra bondad que, a mi parecer, tienen clara resonancia con la visión de santo Tomás de Aquino sobre el papel de las pasiones en la vida moral (y debo añadir que ello, desde cierto punto de vista, ayuda a compensar la lectura unilateral que ofrece Freud de la tragedia griega). Si uno pudiera encontrar en el Aquinate al modelo del portavoz de una genuina moralidad de la afectividad humana, como pienso que se podría hacer, se debe a su casi singular afirmación sobre el papel esencial que juegan las pasiones en la búsqueda de la excelencia moral. En este sentido, el connotado teólogo moral, Servais Pinckaers, establece que la mirada de Tomás de Aquino sobre las pasiones en la vida moral, particularmente como lo subraya en su Summa Theologiae, marca un logro 'único' de 'notable genialidad'.

En lo que sigue intentaré corroborar este aserto de Pinckaers. Con este fin, enfocaré particularmente dos puntos: primero, la visión moral de la afectividad humana, sugerida en la decisión de santo Tomás de situar su sistemático estudio sobre la emoción, el tratado de las pasiones del alma, en la Secunda Pars de la Summa Theologiae, que se encuentra en la sección moral de la Summa. Segundo, su insistencia tanto en que las pasiones juegan un papel que colabora activamente en el trabajo de la virtud moral, como en que la emoción humana se convierte en racional por participación, insistencia debida a Aristóteles, pero que cobra alturas que hubieran sorprendido al mismo Filósofo. En este último punto, el Aquinate entra en conflicto con la tradición filosófica predominante. En una palabra, su posición se ubica entre dos extremos que frecuentemente podemos apreciar en la historia del pensamiento

${ }^{1}$ Servais Pinckaers, The Sources of Christian Ethics, 1995, Washington D. C., Catholic University of America Press, trad. de Mary T. Noble, p. 224; del mismo autor, cfr. "Reappropriating Aquinas's Account of the Passions", The Pinckaers Reader: Renewing Thomistic Moral Theology, John Berkman y C. S. Titus (eds.), 2005, Washington D. C., Catholic University of America Press, p. 273-4. 
filosófico: uno, que excluye la emoción de la acción moral; el otro, que identifica a la emoción con el deber moral como tal.

\section{La importancia de situar el Tratado de las pasiones en la sección moral de la Summa Theologiae}

Movimientos del apetito sensitivo irracional

Santo Tomás vincula las emociones, o la afectividad humana en general, al apetito sensorial (o sensitivo). Las enlaza, en otras palabras, a nuestra inclinación interna irracional por bienes o males materiales, percibidos por los sentidos, y a la eventual procuración o evasión de dichos bienes o males perceptibles. De este modo, define a las pasiones como movimientos de esta inclinación irracional inferior por los bienes o males perceptibles. ${ }^{2}$ Contrario al uso en el lenguaje moderno, en el que frecuentemente su connotación refiere a una vehemencia afectiva, el término pasión, para el Aquinate, significa simples movimientos sensibles (irracionales) del alma. ${ }^{*}$ Consciente de ello, utilizaré los términos 'pasión' y 'emoción' como toscas traducciones equivalentes al latín passio.

Santo Tomás reconoce que la experiencia humana de la emoción nos confronta con una paradoja: por un lado, porque tenemos en común con los animales una orientación afectiva interna por los bienes materiales creados, nuestras pasiones son expresión de la parte 'animal' de nuestra naturaleza humana; por el otro, no somos solamente animales, de tal modo que experimentamos la emoción de forma única. El entrejuego que nuestro apetito sensitivo inferior comparte con la razón y la

${ }^{2}$ En Summa Theologiae (en adelante ST) I-II, q. 22, a. 3; sed contra, el Aquinate cita la definición de pasión de Juan Damasceno, localizada en De fide orth., II, 22 [ed. Buytaert, 132]; cfr. también Nemesio de Emesa, De nat. hom., 15 [ed. Verbeke-Moncho, p. 93]: "la pasión es un movimiento de la facultad del apetito sensible en respuesta a la percepción de algo bueno o malo" [passio est motus appetitivae virtutis sensibilis in apparitione boni et mali].

* En este caso 'irracional' (animal-like) no significa 'anti-racional', sino 'no racional'. $[N \operatorname{del} T$.] 
voluntad, nuestras facultades superiores, dispone una nueva dinámica completa en la experiencia humana de la emoción, ${ }^{3}$ puesto que, sumada a nuestra orientación afectiva interna por los bienes materiales creados, de los cuales surgen las emociones, gozamos de una orientación apetitiva más alta: aquella de la voluntad, que nos ordena internamente hacia el bien universal, hacia el summum bonum.

\section{Un primer paso necesario en la búsqueda humana de la alegría y del bien mayor}

Este primer paso nos ayuda a entender por qué Santo Tomás sitúa su exhaustivo estudio sobre la afectividad humana, el tratado de las pasiones, en el corazón de su sistemático análisis de la moralidad humana, a saber, en la Secunda Pars de su Summa Theologiae. Más aún, el tratado de las pasiones, como ha observado Pinckaers, comprende el tratado más extenso de toda la Summa, pues abarca veintisiete cuestiones que incluyen ciento treinta y dos artículos. ${ }^{4}$ Tal estudio

3 "Las pasiones, consideradas en sí mismas, son comunes a los hombres y a otros animales; pero en cuanto imperadas por la razón (a ratione imperantur) son propias de los hombres", ST I-II, q. 24, a. 1 ad 1. Como observa Pinckaers en "Reappropriating Aquinas's Account of the Passions", p. 276: "[Al principio del tratado de las pasiones] el problema de la cualidad moral de las emociones bien sitúa en relación con la razón y la voluntad, y les atribuye una dimensión que no tienen entre los animales. Santo Tomás las considera como emociones humanas, integradas al compuesto humano." Al respecto, véase también Stephen Loughlin, "Similarities and Differences between Human and Animal Emotion in Aquinas's Thought", Thomist, 2001, 65, p. 45-65.

${ }^{4}$ Cfr. Pinckaers, op. cit., p. 273, en donde también examina el trabajo anterior del Aquinate, en el cual el doctor angélico muestra un interés claro, y cada vez mayor, por las pasiones. En este tratado, en la Prima-Secundae Pars, santo Tomás ofrece un estudio sistemático de las pasiones en general, incluida su moralidad (q. 22-25); la naturaleza, causas y efectos de la pasión del amor (q. 26-28); la naturaleza de las pasiones del odio (o disgusto) y de la concupiscencia (q. 29-30); la naturaleza, causas, efectos y moralidad de las pasiones de la delectación (q. 31-34); la naturaleza, causas, efectos, remedios y moralidad de las pasiones del dolor y la tristeza (q. 35-39); la naturaleza de las pasiones de la esperanza y la desesperación (q. 40); la naturaleza, objeto, causas y efectos de la pasión del temor (q. 41-4); la naturaleza de la pasión de la audacia (q. 45); y la naturaleza, causas, remedios y efectos de la pasión de la ira (q. 45-8). 
empequeñece los únicos precedentes históricos conocidos, de los cuales se sirve el Aquinate: el pequeño tratado de las pasiones de Nemesio de Emesa, que se encuentra en su De natura hominis; y, siguiendo a éste, el tratado de las pasiones de Juan Damasceno, en De fide ortodoxa (Aristóteles no nos dejó un tratado sistemático sobre las pasiones). ${ }^{5}$

El que santo Tomás sitúe el tratado de las pasiones en la sección moral de la Summa es más bien sorprendente, si recordamos que la beatitud eterna es el telos dominante de la vida moral y, subsecuentemente, principio rector de toda la Secunda Pars de la Summa. De hecho, a primera vista uno esperaría que hubiera situado su tratado de las pasiones antes, en la Prima Pars de la Summa, específicamente en el tratado del alma humana (q. 75-90), en cuyo prólogo se propone el estudio "de la esencia del alma, sus potencias y sus operaciones" (q. 75). Como movimientos del apetito sensible (una potencia del alma), las emociones ciertamente deberían ser incluidas entre las operaciones del alma.

${ }^{5}$ El primero, escrito entre 390 y 400 A. D. y falsamente atribuido a Gregorio de Nisa en la Edad Media, estudia las pasiones de la concupiscencia, delectación, tristeza, ira y temor (para este tratado, en la edición crítica del texto latino que santo Tomás conoció, cfr. "Némésius d'Émèse De natura hominis. Traduction de Burgundio de Pise", eds. G. Verbeke y J. R. Moncho, en Corpus latinum commentariorum in Aristotelem graecorum. Suppl. 1, 1975, Leiden, E. J. Brill, p. 92-126). Juan Damasceno reproduce el tratado de Nemesio casi palabra por palabra, al examinar en el libro II de su De fide orthodoxa las pasiones del gozo, tristeza, temor e ira; cfr. De fide orthodoxa. Versions of Burgundio and Cerbanus, 1955, St. Bonaventure, N. Y., Franciscan Institute, ed. E. M. Buytaert, p. 119-47. El P. Bonifatius Kotter, "Patristische Texte und Studien", vol. 2, p. xxix (Die Schriften des Johannes von Damaskos, 1969-88, Berlin-New York, Walter de Gruyter, 5 vols.), ha identificado setenta pasajes en el De fide orthodoxa en los cuales las notas de Juan Damasceno con respecto a psicología y antropología pueden ser rastreadas hasta Nemesio. Para una comparación entre el tratado de las pasiones de santo Tomás con los de Nemesio y Juan Damasceno, véase la nota anterior. También, con respecto a Aristóteles, encontramos algunos comentarios relacionados con la virtud moral y la concupiscencia en $E N$ (especialmente en II, 5-6; III, 6-7; IV, 5-6; y VII, 3-10); en cuanto a cómo las pasiones afectan la disposición de una audiencia a la que se dirige un determinado argumento, en $R h$ (especialmente en II, 2-14). Estos comentarios producen lo que Mark Jordan llama "detalles innumerables y sentencias aplicables", "Aquinas's Construction of a Moral Account of the Passions", Freiburger Zeitschrift für Philosophie und Theologie, 1986,33, p. $75-8$. 
Pero santo Tomás prefiere el ambiente de la vida moral al estudio, más metafísico, sobre el alma humana, frente al cual sitúa estrictamente su estudio de las emociones. Tal giro le permite concluir que las emociones son un primer paso necesario en nuestra búsqueda de la felicidad, en nuestra esperanza de lograr el fin de la visión de Dios. Aunque las pasiones nos inclinan hacia los bienes inferiores, los bienes materiales, que no nos pueden llenar por completo puesto que somos seres racionales, dichos bienes participan de la bondad misma -son, después de todo, 'bienes'. Finalmente, estos bienes inferiores provisionales permanecen ordenados al bien perfecto y suficiente (summum bonum), a la perfección absoluta de Dios. ${ }^{6}$

Al estar inclinados internamente a bienes materiales limitados, nos encontramos ya en el camino establecido hacia el bien mayor. Estamos dispuestos en una trayectoria, aunque sólo en sus etapas iniciales, que tiene como punto final a Dios mismo. Insiste: la vida de excelencia espiritual y moral no es privación del disfrute de los placeres terrenos y materiales. Al contrario, tal disfrute es fundacional para la vida de santidad y perfección moral; la vida de santidad incluye nuestros deseos, no lucha contra ellos. En una palabra, Dios quiere que todos nosotros gocemos, en beatitud, de los bienes materiales y demás, no sólo de nuestras partes 'cerebrales'; no quiere que nuestro amor por Él excluya el deseo y el amor por los bienes terrenales creados.

Deberíamos enfatizar que esta percepción sobre el papel primordial, indispensable, que juega la emoción en el esfuerzo humano por el summum bonum, muestra cierta impronta platónica en el pensamiento del Aquinate. Aunque ambivalente al respecto, Platón, no obstante, entiende bien que nuestros impulsos irracionales inferiores (que denomina espíritu y apetito) no deben ser suprimidos como tales o

\footnotetext{
${ }^{6}$ Michael Sherwin subraya bien el logro del Aquinate en unir, más que separar, la felicidad última con la felicidad terrena, que los poderes naturales del hombre pueden alcanzar por sí mismos: "el Aquinate es capaz de describir la [terrena noción de] felicidad de Aristóteles como una participación de la postrera beatitud [...] Es una verdadera participación de la beatitud celestial", "In What Straits They Suffered: St. Thomas's Use of Aristotle to Transform Augustine's Critique of Earthly Happiness”, Nova et Vetera, Eng., 2005, 3, p. 333.
} 
inhibidos excesivamente. En cambio, son como corceles que, necesitados de correr en tanto indómitos, configuran el movimiento 'erótico' del cual dependemos para impulsarnos hacia la más alta Belleza y el Bien supremo. La razón actúa como un auriga, para usar la legendaria alegoría platónica, gracias a quien la fuerza motriz proporcionada por los corceles es adecuadamente aparejada y ordenada hacia la más alta de las formas, el Bien. Esto se sostiene incluso si, como admite Platón, tal aparejamiento "por necesidad trae un sinnúmero de problemas [al auriga]". 7

De cualquier forma, los escritores espirituales cristianos, tanto antes como después de santo Tomás, se han mostrado renuentes a reconocer el papel fundacional que juega el disfrute de los bienes materiales limitados en nuestra búsqueda de la excelencia espiritual. En medida no pequeña, esto se debe a los efectos desordenantes del pecado en la afectividad humana y a la constante influencia del desdén estoico por la emoción humana. ${ }^{8}$ Tal desdén ha llevado a que la tradición espiritual

${ }^{7}$ Pl., Phdr, 246-56, (1937, New York, Random House, trad. de Benjamin Jowett); para otros comentarios sobre la división del alma, $\mathrm{cfr}$. $R$, IV. La ambivalencia platónica deriva de su desdén por el cuerpo, lo cual seguramente incide en por qué en Phd., 64-84, habla de cuánto debe uno de alejarse de los placeres sensibles para lograr la obtención de la verdadera alegría espiritual. Esto explica, sin duda, por qué santo Tomás rara vez comenta la visión platónica sobre la moralidad de las pasiones (para un pasaje en el cual el Aquinate se refiere a la postura de Platón, V. ST I-II, q. 34, a. 3). La carta encíclica inaugural del Papa Benedicto XVI, Deus caritas est, que inicia con un intento por reconstruir una comprensión renovada y purificada del eros y del agape, se aproxima a la comprensión platónica del eros, cuando escribe que el eros es una forma del amor que los griegos veían "como un arrebato, una 'locura divina' que prevalece sobre la razón, que arranca al hombre de la limitación de su existencia y, en este quedar estremecido por una potencia divina, le hace experimentar la dicha más alta", $\left(\mathrm{n}^{\circ} 4\right.$, trad. Libreria Editrice Vaticana).

${ }^{8}$ Las referencias a textos de los estoicos (principalmente de Cicerón, Séneca y Virgilio) aparecerán cerca del final de este ensayo. Para los numerosos textos en los que santo Tomás critica la visión estoica, y que abarcan toda su carrera, cfr. mi trabajo "The Passions of Christ's Soul in the Theology of St. Thomas Aquinas", Beiträge zur Geschichte der Philosophie und Theologie des Mittelalters, Neue Folge, 61 (2002, Münster, Aschendorff), 282, n. 46 (dos ejemplos en ST I-II, q. 59, a. 3: Tomás tacha la visión estoica de 'irracional' [hoc irrationabiliter dicitur]; y, en In Ioan., 11, 5 [n $\left.{ }^{\circ} 1535\right]$, se refiere al desdén estoico por la emoción como 'excesivamente inhumano' [valde inhumanum]). Para un análisis de la influencia del estoicismo en el pensamiento de santo Tomás, incluyendo la moralidad de las pasiones, cfr. 
cristiana relegue las pasiones, o a la afectividad humana en general, a las márgenes de la vida espiritual, concibiéndolos comúnmente como obstáculos enemigos que deben ser evitados. ${ }^{9}$ Con imaginación expresiva, Pinckaers describe el peligro de denigrar este elemento esencial de la vida humana:

E. K. Rand, Cicero in the Courtroom of St. Thomas Aquinas, "The Aquinas Lecture, 1945", 1946, Milwaukee, Marquette University Press; Gerard Verbeke, The Presence of Stoicism in Medieval Thought, 1983, Washington, D. C., Catholic University of America Press, p. 1-19; y Michel Spanneut, "Influences stoïciennes sur la pensée morale de S. Thomas d'Aquin", The Ethics of St. Thomas Aquinas: Proceedings of the Third Symposium on St. Thomas Aquinas' Philosophy, L. J. Elders and K. Hedwig (eds.), "Studi tomistici 25", 1984, Ciudad del Vaticano, Libreria Editrice Vaticana, p. 50-79.

${ }^{9}$ Una excepción a esta regla general será el gran místico del siglo XII, Bernardo de Clairvaux, quien enfatiza fuertemente el lado afectivo del amor humano por Dios, como en su Sermón sobre el Cantar de los Cantares. Pinckaers, op. cit., p. 274, señala el influyente Manuale Theologiae Moralis de D. M. Prümmer (1953 ${ }^{11}$, Freiburg im Breisgau) como un buen ejemplo - a pesar de la pretensión de haber sido escrito "según los principios de santo Tomás de Aquino"- de hostilidad moral hacia las emociones, dado que el tratamiento de las pasiones se encuentra en una sección titulada "Sobre los enemigos de los actos voluntarios (De hostibus voluntarii)." Uno podría mencionar tan sólo dos ejemplos de escritores espirituales que vivieron poco antes del Aquinate y que repiten el cargo estoico de que las pasiones son las "enfermedades" del alma: Guillermo de St. Thierry (d. 1148), De nat. corp. et an. (PL 180, 714), y Ricardo de St. Victor (d. 1173), De statu int. hom., I, 9 y 34 (PL 196, 1122 y 1141). También se puede agregar a Gregorio de Nisa, quien, como Michael Dauphinais afirma ("Languages of Ascent: Gregory of Nyssa's and Augustine of Hippo's Exegeses of the Beatitudes", Nova et Vetera, Eng, 2003, 1, p. 151-2), entiende a la pasión como manifiestamente indómita, deseo desordenado como tal; cfr. su Homilia 5, núms. 131-3, en Gregory of Nyssa: Homilies on the Beatitudes: An English Version with Commentary and Supporting Studies. Proceedings of the Eighth International Colloquium on Gregory of Nyssa, 1998, Paderborn, 14-18 September, Hubertus R. Drobner y Albert Viciano (eds.), 2000, Boston, Brill. El influyente pensador luterano moderno, Dietrich Bonhoeffer (The Cost of Discipleship, 1995, New York, Touchstone, p. 127 [originalmente 1959 por SCM Press]) prevalece en la herencia cristiano-estoica cuando escribe lo siguiente sobre la emoción de la cólera: "Jesús no aceptará la distinción común entre justa indignación y cólera injustificada. El discípulo debe estar completamente libre de cólera, pues ésta es una ofensa tanto contra Dios como contra el vecino." Para un reciente ensayo teológico que argumenta que la vida cristiana debería estar exenta de la emoción de la cólera, cfr. Paul Lauritzen, "Emotions and Religious Ethics", Journal of Religious Ethics, 1988, 16, p. 307-24; cfr. también su Christian Belief and Emotional Transformation, 1992, Lewisburg, Bucknell University Press. 
Algunos piensan que [la excelencia moral] sólo puede alcanzarse suprimiendo nuestros sentimientos y pasiones en una especie de automutilación. ¿Pero querríamos a un domador que empleara tales métodos? ¿No nos burlaríamos de él si nos mostrase tigres sin colmillos ni garras? A nivel moral tales tácticas serían más serias, por no decir ridículas, dado que las mociones sensibles existen y actúan dentro de nosotros. ${ }^{10}$

Entonces, para romper filas con la escuela de pensamiento de inspiración estoica, y para enfatizar que no podemos asegurar una vida feliz - meta de la acción moral- sin las emociones, el Aquinate toma la medida, sin precedentes, de situar las pasiones en el corazón de su estudio sobre la moralidad humana. Dicha maniobra táctica subraya el punto de que no podemos desechar a las emociones de "la consideración universal de agente moral", como lo establece Pinckaers. ${ }^{11}$ Nuestro apetito sensible, nuestra inclinación irracional por bienes inferiores, actúa como una especie de semilla, gracias a la cual germina y crece nuestro deseo de poseer el Bien primero. En este Bien nuestro entero anhelo apetitivo (nuestro anhelo 'erótico', para usar la terminología platónica), tanto intelectual como sensitivo, tanto racional como irracional, encuentra total descanso. Sin duda, tal anhelo cuenta en la aserción del Aquinate, más bien audaz, si no controvertida, en cuanto a que la pasión del amor, amor, actúa como la fuente de dos virtudes teologales, a saber, esperanza y caridad. ${ }^{12}$ En una palabra, el hombre

${ }^{10}$ Servais Pinckaers, The Pursuit of Happiness-God's Way: Living the Beatitudes, 1998, New York, Society of St. Paul, trad. de Mary T. Noble, p. 62-3.

${ }^{11}$ Pinckaers, "Reappropriating Aquinas's Account of the Passions", p. 273.

12 "[La virtud de] la esperanza es anterior a la caridad. Esto se pone en evidencia por el hecho de que la esperanza y todo movimiento del apetito [la caridad incluida] se deriva del amor (ex amore derivatur)." ST II-II, q. 17, a. 8 (cfr. también ad 2). Con ello santo Tomás quiere decir que todos los movimientos apetitivos orientados hacia el bien, incluso aquellos del más puro tipo espiritual, tienen una simple connaturalidad afectiva, tal como su cimiento: "todo movimiento hacia una cosa o el descanso en ella [incluso las virtudes de la esperanza y de la caridad] proviene de cierta connaturalidad (connaturalitate) o proporción (coaptatione), que pertenece a la naturaleza del amor (amor)". ST I-II, q. 27, a. 4. Pinckaers, op. cit., p. 276, añade que, cuando el doctor angélico examina los efectos de la pasión del amor, emplea términos que "evocan directamente el lenguaje y las experiencias del misticismo cristiano" 
entero está hecho para ser movido desde dentro, movido incluso por su apetito sensible inferior, hacia la adquisición de la felicidad eterna, hacia el adecuado fin de la vida humana.

\section{La emoción humana se vuelve racional por participación mediante el trabajo de la virtud moral}

\section{Enfrentando atracciones apetitivas}

Como bien sabe santo Tomás, sólo en forma extremadamente rara nuestros anhelos del apetito intelectual y sensitivo trabajan armónicamente hacia el logro de nuestro verdadero fin. Aunque las facultades superiores del alma humana, razón y voluntad, contienen un natural 'poder de gobierno' (imperium) sobre las facultades irracionales inferiores, dicho poder no es absoluto. El apetito sensitivo guarda una especie de cuasi-autonomía; como resultado, el apetito sensitivo inferior, inclinado como está hacia los bienes sensuales provisionales, permanece siempre dispuesto a rebelarse contra el imperium de la razón y la voluntad, o, a la inversa, a consentirlo.

Lo anterior hace que se levante una auténtica lucha dentro de nosotros, un choque entre atracciones apetitivas contrarias: una, hacia los bienes materiales (la atracción sensitiva inferior); la otra, hacia nuestro bien mayor, el bien de la razón (la atracción intelectual superior). La tradición teológica cristiana ha empleado el término concupiscencia para referirse a este contexto de tensiones apetitivas en la persona humana. En la carta a los romanos (7, 14-24), san Pablo la describe con crudeza como una "guerra entre sus miembros" haciendo que "no haga el bien que quiere". Toda persona, en ocasiones, se encuentra a sí misma sujeta a la inmoderada atracción de las emociones que, variando en gradación, enfrenta nuestro mejor juicio. En pocas palabras, la

(por ejemplo, unión, morada mutua, éxtasis, ardor y herida). Agradezco a Vivian Boland, OP, por llamar mi atención en torno a este punto (en conversación personal). 
concupiscencia encapsula el paquete entero de efectos desordenantes que el pecado ha inflingido sobre las pasiones o sobre la afectividad humana en general. ${ }^{13}$ Pinckaers, utilizando de nuevo una vívida imaginería metafórica, expresa bien el estado de desorden interior que se refiere a la experiencia de cada individuo humano:

Si miramos dentro de nosotros mismos y estudiamos un poco nuestra conciencia y nuestras reacciones, podemos percibir las borrosas figuras de todo tipo de animales que viven ahí y nos amenazan... Encontramos al orgulloso y tiranizante león, al gallo fanfarrón, al vanidoso pavo real, al gato lisonjero y al astuto zorro... Descubrimos al brutal rinoceronte y al perezoso elefante, al asustadizo conejo y al sensual cerdo, al perro feroz y a la corrosiva lombriz... iQué poder y firmeza son necesarios, qué clarividencia y habilidad, si hemos de controlar todos estos instintos, si hemos de conducirlos hacia la curación y llamarlos a la obediencia y servicio de la caridad! El auto-dominio completo es un trabajo largo y exigente. ${ }^{14}$

\section{El limitado poder de la razón y la voluntad para gobernar el apetito} sensible

Para manifestar esta relación única que existe entre el apetito sensible inferior y las potencias intelectuales superiores, y el conflicto apetitivo resultante de ello, el Aquinate recurre a un término acuñado por Aristóteles: principatus politicus. ${ }^{15}$ Con este término, santo Tomás, siguiendo

${ }^{13}$ En santo Tomás, el término concupiscencia connota un estado de desorden general en la condición humana, en el cual el apetito sensible permanece desordenadamente inclinado hacia los bienes mudables inferiores. Cfr. $S T$ I-II, q. 82, a. 3 y a. 4 ad 1; q. 91, a. 6; De malo, q. 3-4; y De veritate, q. 25, aa. 6-7. Para un detallado análisis sobre este punto, cfr. M. M. Labourdette, "Aux origines du péché de l'homme d'après Saint Thomas d'Aquin," Revue thomiste, 1985, 85, p. 357-98; y mi trabajo The Passions of Christ's Soul in the Theology of St. Thomas Aquinas, p. 294-300.

${ }^{14}$ Pinckaers, The Pursuit of Happiness, p. 62.

${ }^{15}$ El texto clásico de santo Tomás en el cual se afirma esto se encuentra en $S T$ I, q. 81, a. 3 ad 2; y en Arist., Pol., I, 5 (1254b2-5) 1966, New York, Random House; las traducciones 
al Filósofo, intenta transmitir una metáfora política por medio de la cual el apetito inferior puede ser ligado a sujetos libres que participan de forma limitada, es decir, mediante su libre consentimiento, en el gobierno de un soberano; en este caso, el soberano sería tanto la razón como la voluntad. Hoy diríamos que la monarquía constitucional corresponde mejor al tipo de modelo político que santo Tomás quiere comparar al 'poder de gobierno' (imperium) que ejercen la razón y la voluntad sobre el apetito sensitivo.

Siguiendo todavía a Aristóteles, el Aquinate designa el cultivo de las virtudes morales (junto con la asistencia de la divina gracia, añadiría él) como la forma en que razón y voluntad ejercen armoniosamente su imperium sobre el apetito sensitivo y sus movimientos, las pasiones. La virtud moral actúa como el vehículo mediante el cual el apetito sensitivo coopera serenamente con su 'soberano', la razón y la voluntad; a la virtud moral corresponde la tarea de 'humanizar' a las emociones, movimientos de nuestro apetito sensitivo inferior.

\section{En deuda con la sabiduría de los griegos}

Si esta comprensión no es única de santo Tomás, en este caso tampoco lo es de Aristóteles. La antigua sabiduría griega, como un todo, percibía la necesidad de equilibrar y humanizar nuestros impulsos irracionales inferiores por medio del papel rector de la razón. No sólo es ésta la visión contenida en la alegoría de la carroza de Platón, sino también, como fue indicado al principio de este ensayo, fue especialmente dramatizada en la celebrada trilogía esquilea, la Orestíada, escrita todo un siglo antes de Aristóteles. Pienso que está contenida, además, en un texto tan antiguo como la Odisea de Homero. Aquí leemos cómo Odiseo sobrevive a su largo viaje de regreso a Ítaca, gracias al equilibrado auto-control que persistentemente ejercita sobre sus im-

de Aristóteles son de Richard McKeon, The Basic Writings of Aristotle. Principatus politicus podría traducirse como poder político y regio [N. del T.] 
pulsos inferiores -en contraste con todos sus compañeros, quienes, eventualmente, pierden sus vidas como consecuencia de su falta de auto-control. Vemos lo anterior en el caso de los rebaños del dios del sol, Helios: a Odiseo y sus hombres les está prohibido comerlos, bajo pena de muerte, pero a los compañeros del héroe les resulta imposible resistir y sucumben al hambre. Lo constatamos también cuando los hombres de Odiseo se entregan a la seducción de las plantas de loto, cuya fruta borra de toda persona la memoria, el recuerdo de su tierra de origen y todo deseo de volver a casa.

Si esta mirada sobre la equilibrada integración de las emociones mediante el gobierno de la razón está contenida en Esquilo y en Platón (a pesar de su posterior ambivalencia) e incluso en Homero, se vuelve por completo explícita en Aristóteles, para quien la virtud moral "está ligada a las pasiones y a las acciones" (el Aquinate aseverará que las pasiones constituyen la 'materia' propia de las virtudes morales). ${ }^{16}$ Más que nada, tal designación significa virtud moral, que involucra la transformación de nuestros deseos y pasiones irracionales inferiores en acciones que se ajustan y participan del genuino bien humano; en acciones que, más que desviarnos de, nos disponen hacia una trayec-

20 toria encaminada hacia nuestro bien mayor.

\section{"Racional por participación”}

Santo Tomás lleva más lejos la noción de principatus politicus y su asociación con la virtud moral; al tiempo que continúa apoyándose en Aristóteles, específicamente en la observación del Estagirita de que el apetito sensible "participa de alguna manera de la razón", ${ }^{17}$ el Maestro dominico forja una doctrina sobre el poder transformador de la virtud moral que se vuelve completamente suya. He aquí cómo.

${ }^{16}$ Arist., EN, II, 6 (1106b15-16); y Santo Tomás, ST I-II, q. 59, aa. 4-5; y q. 60, a. 3. Cfr. también Nemesio de Emesa, De natura hominis, 31 (ed. Verbeke-Moncho, 126); y Alberto Magno, De bono, trad. 1, q. 5, a. 1 ad 4 (ed. Coloniensis, 74).

${ }^{17} \mathrm{EN}, \mathrm{I}, 13$ (1102b13-14). 
En su 'psicología participada', como se podría llamar a la visión del doctor angélico sobre el alma humana, las potencias irracionales inferiores (incluido el apetito sensitivo) fluyen hacia y participan de las potencias intelectuales superiores, permaneciendo todas ellas ordenadas hacia y atraídas por dichas potencias superiores. Debido a que conserva su cuasi-autonomía, es decir, la habilidad de obedecer (o desobedecer) por sí mismo al imperium de la razón, el apetito sensitivo disfruta de una participación privilegiada en y hacia los poderes superiores, razón y voluntad. Se deleita por una sinergia única con la dimensión racional de la persona humana.

Es el caso, especialmente, cuando concierne a un acto virtuoso, esto es, una ejecución (electio) por la voluntad, de un juicio de la recta razón en cuanto a lo apropiado (o no apropiado) de un momento dado de emoción (este juicio está hecho a la luz de la verdad de la persona humana y de cómo el bien sensible en cuestión está ordenado hacia el bien mayor). ${ }^{18}$ Dispuesto con sencillez, dado que el apetito sensitivo debe otorgar su consentimiento al mandato de la voluntad de que llevará a cabo dicho juicio de la recta razón, se sigue que este apetito inferior puede actuar como principio activo, como fuente, del comportamiento virtuoso. La virtud moral, en otras palabras, triunfa al convertir a las mismísimas emociones en movimientos orientados hacia la virtud. De esta forma, el Aquinate no vacila en aseverar que el apetito inferior, nuestra inclinación irracional por los bienes materiales, posee la capacidad de convertirse, por este mismo acto, en "racional por participación". ${ }^{19}$ No racional per se: las pasiones se

${ }^{18}$ Aquí podemos ver cuán esencial es la virtud de la prudencia para vivir apropiadamente en relación a nuestras emociones, ya que la prudencia permite a la recta razón saber cuándo una inclinación particular hacia un bien sensible se alinea con nuestra orientación al bien primero. Para un excelente estudio sobre la recta razón como regla y medida de los actos humanos, cfr. Laurent Sentis, "La lumière dont nous faisons usage. La règle de la raison et la loi divine selon Thomas d'Aquin", Revue des sciences philosophiques et théologiques, 1995, 79, p. 49-69.

${ }^{19}$ In Ethic., libro I, lect. 13 (n $\left.{ }^{\circ} 242\right)$; cursivas mías (1993, Notre Dame, Ind., Dumb Ox Books, trad. de C. I. Litzinger). Santo Tomás subraya su posición con mayor profundidad en tres loci principales: ST I-II, q. 56, a. 4; Quaestiones disputatae De virtutibus in communi, 
vuelven racionales por la colaboración co-optada y activa con la razón y la voluntad; de esta manera, santo Tomás las considera racionales por participación.

Como veremos, al profundizar en ello, esta enseñanza resulta sumamente destacable. Prima facie, parece sinsentido sostener que la emoción puede dar origen a los actos virtuosos, o participar de la racionalidad humana. Después de todo, las pasiones brotan de la parte irracional de la persona humana y la virtud no es otra cosa que la ejecución de la voluntad de lo que es juzgado cognoscitivamente como comportamiento adecuado de la razón. La racionalidad humana y el libre albedrío, no la emoción, hacen virtuoso un acto.

Al mostrarse de acuerdo en que la virtud consiste primera y principalmente en un acto de la voluntad - "el principal acto de la virtud moral" afirma, "es la elección (electio), y ésta es un acto de la razón"-_20, el Aquinate entiende que no consiste de forma necesaria en un acto de la voluntad exclusivamente. De ninguna manera sostendría que nuestras pasiones y deseos tienen, o al menos deberían tener, poco o nada que ver con nuestras obligaciones morales, que deberíamos hacer lo que debemos hacer sin tomar en cuenta nuestras pasiones y deseos.

22 Para ser más claros: nuestras emociones impactan significativamente en la forma en que pensamos y elegimos.

a. 4 ("Si los apetitos irascible y concupiscible pueden ser sujetos de la virtud"), lo cual fue escrito justo después de terminar la Prima Secundae Pars de la Summa; y III Sent., d. 33, q. 2, a. 4, qla. 2. El estudio clásico sobre esta cuestión es el de M. D. Chenu, "Les passions vertueuses. L'anthropologie de saint Thomas", Revue philosophique de Louvain, 1974, 72, p. 11-18; e idem, "Body and Body Politic in the Creation Spirituality of Thomas Aquinas", Listening, 1974, 13, p. 214-32. Para otra excelente lectura al respecto, cfr. William Mattison, "Virtuous Anger? From Questions of Vindicatio to the Habituation of Emotion", Journal of the Society of Christian Ethics, 2004, 24, p. 159-79; y Bonnie Kent, The Virtues of the Will: The Transformation of Ethics in the Late Thirteenth Century, 1995, Washington, D. C., Catholic University of America Press.

${ }^{20}$ ST I-II, q. 56, a. 4, arg. 4; Qu. disp. De virt. in comm., a. 4, arg. 2. La primera parte de esta frase es una cita de Aristóteles, EN, II, 6 (1106a36); y VI, 2 (1139a22-3). 
El caso de la continencia: hacer el bien sin el deseo afectivo por él

La discusión de santo Tomás sobre la virtud de la continencia y de cómo difiere de la virtud de la templanza puede ayudar a clarificar qué quiere decir que las emociones se vuelvan racionales por participación. Aquí, el Aquinate se inspira, una vez más, en Aristóteles, aunque resulta más explícito que el Estagirita en delinear las implicaciones.

El individuo continente es la persona que actúa virtuosamente, pero sólo después de sostener una lucha contra los desordenados deseos corporales (el continente difiere del incontinente en que éste sucumbe a sus desordenados deseos corporales, $\mathrm{y}$, así, actúa contrariamente a sus principios, contrariamente a lo que sabe que debe hacer). ${ }^{21}$ Aunque seducido por sus deseos sensuales, la persona continente, a diferencia de la incontinente, no cede a tales deseos y persiste en conseguir el bien de la razón: "el hombre continente debe ser elogiado -observa el dominico-puesto que es dominado no por el deseo sensual [como el incontinente], sino por la razón". ${ }^{22}$

Sin embargo, el problema del individuo continente se centra en el hecho de que lucha contra fuertes deseos de placeres corporales no acordes a su mejor juicio. Por ello, Aristóteles afirma que tal persona "actúa según la decisión [i. e., según el juicio racional], no según el apetito [o el deseo sensual)". ${ }^{23}$ La persona continente hace lo correcto, aunque no porque tenga el deseo afectivo por ello. De otra manera: el individuo continente realiza la acción virtuosa por medio de la voluntad pura solamente, no por medio de la ayuda de sus pasiones.

Si la persona continente ha de lograr la completa perfección moral, debe alcanzar una adecuada regulación de sus deseos sensuales o, más

${ }^{21}$ Aristóteles afirma que en los individuos continentes es "la razón la que derechamente les aconseja y excita hacia las mejores acciones. Pero al propio tiempo, es patente [...] otro principio que por su naturaleza está al margen de la razón y que mueve guerra y resiste a la razón," EN, I, 13 (1102b17-19); cfr. también VII, 9-10 (1151a30-1152a35).

${ }^{22}$ In Ethic., libro VII, lect. 9 ( $\left.{ }^{\circ} 1443\right)$.

${ }^{23} E N$, III, 2 (1111b15). 
generalmente, de su orientación afectiva interna por los bienes materiales creados. Debe ser bueno no sólo en su juicio racional sino también en todos sus deseos internos. En contra de esta postura, por ejemplo, Immanuel Kant sostiene (como veremos) que deberíamos observar nuestro deber moral a pesar de lo que deseamos: la vida moral debería ser una vida de gozo, tanto afectiva como espiritualmente. Esto sólo puede ocurrir cuando actuamos conjuntamente bajo el juicio racional y bajo el deseo sensual, cuando nuestros actos virtuosos fluyen de nuestras pasiones y deseos: "pertenece a la perfección del bien moral que el hombre se mueva al bien no sólo según la voluntad, sino también según el apetito sensitivo", insiste santo Tomás. ${ }^{24}$

El caso de la templanza: hacer el bien con el deseo afectivo por él

El Aquinate entiende, precisamente, que se puede afirmar lo anterior del individuo por completo moderado. La persona que ha adquirido el hábito, el carácter (habitus), de ser moderado experimenta poca o ninguna atracción desordenada por parte de su apetito concupiscible. Es atraído por su apetito concupiscible, aunque hacia el bien racional, mientras que sus deseos internos lo asisten para actuar de manera moderada. Lleva a cabo el acto virtuoso no mediante el poder de la pura voluntad sola sino con la ayuda de sus pasiones. De esta forma, incluso sus deseos son moralmente encomiables. Tal persona actúa con placer y prontitud, encuentra alivio, y no gravoso afán, en vivir de manera virtuosa. ${ }^{25}$ Esta persona ha logrado la meta de la vida moral.

La regulación de los placeres asociados al sexo, que más específicamente conciernen a la virtud de la castidad (la templanza vigila el disfrute equilibrado del placer corporal en general), ilustran bien cómo la persona moderada (o casta) difiere de la continente. Mientras que tanto el individuo casto como el continente hacen lo que manda

${ }^{24}$ ST I-II, q. 24, a. 3.

${ }^{25}$ Cfr. ST I-II, q. 24, a. 3 ad 1. 
la razón en cuanto al placer sexual se refiere, la persona continente hace tal cosa mediante una lucha contra los deseos de placer sexual ilícito. Al contrario, el individuo verdaderamente casto no experimenta tal batalla. Esta persona disfruta los buenos deseos afectivos, castos deseos, y ello le auxilia para conseguir el bien de la razón. Santo Tomás argumentaría que, si bien ambos observan la obligación de la castidad, queda clara la diferencia moral entre los dos. Uno ha adquirido el carácter (habitus) de ser casto, lo que resulta en deseos internos ordenados correctamente, mientras que el continente simplemente practica la castidad $\sin$ tener deseos castos. Así lo muestra en un pasaje clave de su comentario a la Ética Nicomaquea:

En estos hombres [dotados del hábito de la virtud moral] casi todo -tanto acciones externas como deseos internos- armoniza con la razón... [Y así, cuando consideramos la diferencia entre las virtudes de la templanza y la continencia, vemos que] el hombre moderado no tiene los malos deseos del continente debido a que su deseo sensual está bien ordenado por el hábito de la templanza... De esta manera, gracias a su hábito de templanza, el hombre moderado no siente deleite alguno en los deseos contrarios a la razón, mientras que el hombre continente está inclinado a tomar un placer no razonable aunque no está seducido por su pasión. ${ }^{26}$

Esto lleva a santo Tomás a concluir, más bien audazmente, que el individuo casto disfruta de un virtuoso apetito concupiscible, que es un apetito concupiscible correcta (o racionalmente) ordenado, el cual ofrece su activa asistencia para vivir con castidad. Su apetito concupiscible está inclinado, por sí mismo, a ser casto; posee el hábito, el carácter, de la virtud de la castidad ("su deseo sensual está bien ordenado por el hábito de la templanza"). ${ }^{27}$ De manera contraria, el continente es frustrado por su apetito concupiscible. Sus deseos

${ }^{26}$ In Ethic., libro I, lect. 13 ( $\left.\mathrm{n}^{\circ} 239\right)$, y libro VII, lect. 9 (n $\left.{ }^{\circ} 1453-4\right)$; cursivas mías.

${ }^{27}$ En EN, I, 13 (1102b29), Aristóteles afirma que en una persona por completo virtuosa, "todo acto [del elemento irracional] armoniza (homophonia [literalmente 'con la misma voz']) con la razón”. 
hablan con voz diferente a la de su razón. En esto descansa la mayor perfección moral.

\section{La emoción como aguijón para los actos de auto-dominio}

Lo que vemos concretamente en el caso del individuo casto conduce a lo que la noción de principatus politicus significa moralmente hablando, $\mathrm{y}$, de manera subsecuente, lo que quiere decir que las emociones se vuelvan racionales por participación. Para mayor claridad en cuanto a este punto, debemos considerar brevemente la noción del ser humano como señor de sus emociones.

Santo Tomás señala que es único de la persona humana, que está dotada de razón y voluntad, el poseer señorío sobre sus acciones, o el disfrutar de la habilidad de gobernar sus movimientos internos que, de otra forma, se opondrían a su juicio racional. ${ }^{28}$ La necesidad de autodominio, no obstante, no se extiende a todas nuestras acciones. Los miembros del cuerpo, por ejemplo, no necesitan de la vigilancia de la razón ni de la voluntad para asegurarse de que hacen como se les ordena; la mano, el pie, el brazo, el cuello siempre observarán los mandatos de la mente, y nunca, por sí mismos, resistirán los mandatos de razón y voluntad. Hablando de manera estricta, no ganamos 'señorío' por el caminar de nuestras piernas o el tornar de nuestras cabezas.

En lo que concierne a nuestro apetito irracional inferior y a sus movimientos, las pasiones, nos encontramos en un reino diferente al de nuestras extremidades. Es el reino de lo verdaderamente humano, esto es, el reino de lo racional (por participación). Debido a que tiene el poder de obedecer o desobedecer el imperium de la razón y la voluntad, el apetito sensible, en su operación, requiere de la adecuada vigilancia de nuestras potencias superiores. En una palabra, el apetito

28 "El hombre se diferencia de las criaturas irracionales en que es dueño de sus actos. Por eso, sólo aquellas acciones de las que el hombre es dueño pueden llamarse propiamente humanas. El hombre es dueño de sus actos mediante la razón y la voluntad”, ST I-II, q. 1, a. 1. 
inferior incita a la persona humana a actos de auto-dominio, ya que sobre las emociones la persona humana puede y debe ganar señorío. Y esto no quiere decir otra cosa más que las emociones incitan a la persona humana a actos de virtud, pues ganar tal auto-dominio pertenece, evidentemente, a la tarea de la virtud moral.

Entonces, en cuanto una emoción nos lleve a ganar señorío sobre ella misma, es planteada para trabajar con nuestras facultades intelectuales superiores. Concluye como acto propiamente humano, como un acto racional, un acto virtuoso. En el caso del individuo casto, arriba mencionado, podemos afirmar que sus deseos de placer sexual concluyen como adecuados racionalmente, como deseos virtuosos, al mismo tiempo que permanecen todos como deseos afectivos. Disfruta con deseos afectivos castos o 'humanizados'.

Justo tan importante como decir que las emociones nos incitan hacia actos de virtud, que el apetito sensitivo actúa como aguijón de la virtud, es afirmar que este apetito inferior es fuente de comportamiento adecuado racionalmente (i. e. virtuoso). El apetito sensitivo humano, nuestra orientación irracional por los bienes materiales creados, genera actos de virtud, como provenientes de un principio o fuente, como si proviniesen de una causa. ${ }^{29}$

En ello vemos cuán lejos lleva el Aquinate su psicología participada: lo que el apetito sensitivo pone en marcha, lo concluyen la razón y la voluntad, mediante un proceso sinérgico transformativo. Recuérdese cómo la Orestíada ilustra dicho proceso transformativo cuando, luego

${ }^{29} \mathrm{Tal}$ como lo establece sucintamente el tomista del siglo XV, Juan Capreolus, al comentar esta enseñanza del Aquinate: "Cada potencia que pueda ser principio de un acto humano, y no está determinado en su naturaleza [...] el obedecer a la razón, puede ser sujeto de una virtud", Defensiones Theologiae Divi Thomae Aquinatis, libro III, d. 33, a.1, fin de concl. 1 (la traducción al inglés se puede localizar en John Capreolus, On the Virtues, 2001, Washington, D. C., Catholic University of America Press, trad. de K. White y R. Cessario, p. 250). Santo Tomás afirma en ST I-II, q. 77, a. 6 ad 2 que la pasión buena puede acrecentar el mérito de una acción, consiguiente al juicio de la razón. Pero no es lo mismo que lo que se discute aquí, lo cual explica bien Capreolus. Es más lo que argumenta el Aquinate en ST I-II, q. 56, a. 4 , a saber, que cualquier potencia del alma que opera como principio de un genuino acto humano debe participar de la racionalidad humana. 
de que las Furias aceptaron subordinar sus deseos instintivos por la venganza de sangre al papel rector de la razón, representado por Atenea y los demás dioses olímpicos, estos deseos fueron transformados y 'humanizados', es decir, fueron integrados, y en consecuencia, creados para colaborar con un sistema de justicia determinado por la razón (esto es, un juicio con un jurado).

\section{El apetito sensitivo inferior como hábito virtuoso}

Dado que el apetito sensitivo participa de la dimensión racional de la persona humana mediante su actuación como fuente de virtud, nada nos impide situar a la virtud moral en esta inclinación irracional inferior por los bienes sensibles. En este punto, santo Tomás es inequívoco: "se sigue que allí [hay una especie de] virtud humana... [la cual] se encuentra en lo que es racional por participación, esto es, en la parte apetitiva del alma". ${ }^{30}$

Una vez que hemos dicho esto podemos, junto con él, hablar del apetito sensitivo como de un hábito virtuoso (habitus), puesto que la virtud no es otra cosa que un habitus, una cualidad del alma, por medio de la cual la repetición de nuestros buenos actos nos inclina a actuar correctamente, o nos dota con una estable habilidad formativa del carácter para actuar bien. ${ }^{31}$ Los apetitos sensitivos son potencias operativas pasivas que son capaces de recibir una formación determinante del carácter (habitus).

Algunos moralistas, señalando un texto de Aristóteles como respaldo, siguen debatiendo si los hábitos virtuosos, dado que nos inclinan a cierto tipo de comportamiento, en realidad enseñan a nuestra libertad. ${ }^{32}$ De cualquier forma, debemos recordar que la facultad de elección, la

${ }^{30}$ In Ethic., libro I, lect. 13 (n $\left.{ }^{\circ} 243\right)$.

${ }^{31}$ III Sent., d. 33, q. 2, a. 4, qla. 2; y Qu. disp. De virt. in comm., a. 4.

${ }^{32}$ El pasaje clave de Aristóteles se encuentra en EN, III, 5 (1114a3-22), en donde el Estagirita establece que, quien ha cultivado el vicioso hábito de la intemperancia o de la injusticia, carece de la habilidad, de la libertad, de ser otra cosa que inmoderado o injusto. 
voluntad, tiene como su objeto al bien universal, el bien de la razón. Dado que los hábitos virtuosos nos inclinan hacia el bien racional, ordenan la voluntad a su objeto adecuado. Al hacer esto aseguran un funcionamiento correcto $\mathrm{y}$, así, el apropiado cumplimiento o florecimiento de la voluntad. Santo Tomás no concibe al libre albedrío como una potencia indeterminada, con un fin radicalmente abierto, indiferente a todo lo que esté frente a él, sea bueno o malo. Más bien, la libertad está determinada y perfeccionada por la inclinación natural de la persona humana hacia el bien, al estar inscrita dentro de ella. ${ }^{33}$ Lo que sostendría, entonces, que los hábitos viciosos enseñan a nuestra voluntad (de hecho, el tipo de hábito mencionado por Aristóteles); justamente lo contrario es el caso de los hábitos virtuosos.

Mediante el crecimiento en la virtud moral, el apetito sensitivo inferior avanza, de ser un poder que se opone, sin importar cuán vigorosamente, al poder de gobierno de la razón y la voluntad, a ser uno que coopera cada vez más con este imperium por medio de sus propios impulsos. No simplemente forzado a someterse a la razón y a la voluntad, el apetito sensitivo es tratado como si fuera un igual, y de este modo, alistado para un servicio activo, colaborador, en la adquisición de virtudes morales. Así, el individuo moderado, como vimos, deja de estar frustrado por los deseos desordenados de placer carnal y, en cambio, disfruta de deseos virtuosos, correctamente ordenados, por dichos placeres. Como lo establece santo Tomás en un pasaje medular:

No es propio de la virtud moral hacer que las facultades sometidas a la razón cesen en sus propios actos, sino que sigan el imperio de la razón ejerciendo sus propios actos. Por lo que, así como la virtud ordena a los miembros del cuerpo ejecutar (exequantur) los actos exteriores debidos, también ordena al apetito sensitivo tener sus propios actos ordenados. ${ }^{34}$

33 "La voluntad no quiere necesariamente todo lo que quiere [...] ya que el bien apetitivo es el objeto de la voluntad", $S T$ I, q. 82, aa. 2 y 3; cfr. también q. 83, a. 3.

${ }^{34} S T$ I-II, q. 59, a. 5, cursivas mías. 
Si esto no sucede, nuestro intento por actuar de manera virtuosa frecuentemente encontrará resistencia por parte de nuestra inclinación irracional inferior por los bienes sensibles. Esto limitará severamente el grado en que el comportamiento virtuoso perfecciona nuestro carácter, dado que nunca nos levantaremos más allá de la virtud de la continencia. Los actos internos provenientes de nuestro apetito sensitivo, las emociones, nunca serán genuinamente 'humanizados'. Para lograr un estado de perfección moral necesitamos volvernos buenos en nuestras emociones y deseos, así como en las elecciones de nuestra voluntad.

\section{Santo Tomás destaca en la Historia del pensamiento filosófico}

Como establecimos al principio de este ensayo, este elemento del pensamiento del Aquinate destaca afortunadamente al compararlo con el ambiente de la historia del pensamiento filosófico. Con la evidente excepción de Aristóteles, los filósofos adoptan típicamente uno de los dos extremos en esta materia: o asignan a las pasiones un papel insignificante en la vida moral, cuando no enemigo, o adjudican a la emoción un papel gobernante, rector, de la vida moral.

Para los primeros, más allá de las ambivalencias de Platón, el estoicismo inaugura la primera escuela de pensamiento filosófico que manifiesta un claro desprecio por la emoción. Fallando al distinguir la pasión -movimiento interno de la inclinación sensitiva por los bienes materiales-de los movimientos de nuestro apetito intelectual -la voluntad-, y preocupados por la habilidad de la emoción para ensombrecer nuestro juicio y estorbar nuestro deber de vivir virtuosamente, los estoicos no consiguen resolverlo de mejor manera que denigrando las pasiones como 'enfermedad del alma'. ${ }^{35}$ La meta de

${ }^{35}$ Para textos de los estoicos que indican un menosprecio por las pasiones, cfr. Cic., Fin., III, 20; Tusc., I, 80; III, 4 y 10; IV, 5-6; Verg., A., IV, 449; y Sen., Cl., 7; Ep., IX, 5, 9 y 85; y De constantia sapientis, VII, 2 (en L. Annaei Senecae Opera omnia quae supersunt, 1833, Augustae Taurinorum, Ex typis Iosephi Pomba, ed. F. E. Ruhkopf, vol. 1, p. 348): “Non est 
la vida moral es la apatheia, la indiferencia por nuestros estados emocionales.

El neoplatonismo seguirá con esta actitud despreciativa para con la emoción humana, percibiendo a la pasión como un impedimento para la ascensión espiritual del alma hacia la unión con el Uno. ${ }^{36}$ Influido por la visión neoplatónica y representante de la voz franciscana, Buenaventura, en los días mismos de santo Tomás, entrará en controversia con el Maestro por la decisión del Aquinate de asignar un asiento al apetito sensitivo en la virtud moral; a fines del siglo XIII, Juan Duns Escoto amplificaría la crítica franciscana. ${ }^{37}$ Ninguno de los dos pensadores franciscanos permitirán a Aquino adscribir un principio activo de conducta virtuosa a nuestra inclinación irracional por bienes materiales, a nuestro apetito sensitivo. Para ellos, la virtud

autem fortior nequitia virtute; non potest ergo laedi sapiens [...] Quod si laedi nisi infirmior non potest [...] iniuria in sapientem virum non cadit" [No es más fuerte la maldad que la virtud; por tanto, un sabio no puede ser dañado [...] Pero si sólo el débil puede ser dañado [...], entonces la injuria no puede caer sobre el varón sabio, $N$. del T.] Para más información al respecto, cfr. mi trabajo The Passions of Christ's Soul in the Theology of St. Thomas Aquinas, 281, n. 44.

${ }^{36}$ Lo cual destaca Platón en Phd., 64-84, en donde, de nuevo, habla de cómo uno debe alejarse del placer sensible, de tal manera que se alcance el verdadero gozo espiritual; probablemente explica por qué el neoplatonismo culpa a las pasiones de buena parte del desorden y sufrimiento humano, tal como Pierre Hadot describe en su Philosophy as a Way of Life: Spiritual Exercises from Socrates to Foucault, 1955, Oxford, Blackwell, ed. Arnold I. Davidson, trad. de Michael Chase, p. 83-100. Comentando este aspecto del trabajo de Hadot, Michael Dauphinais escribe: "Las pasiones debilitan a los seres humanos; los ejercicios espirituales de los filósofos curan esta enfermedad [...] Ser un neoplatónico significa que uno se sujete a una serie de ejercicios espirituales progresivos, que lo lleven lejos de la perturbación de las pasiones, hacia la unión con el Uno", "Languages of Ascent: Gregory of Nyssa's and Augustine of Hippo's Exegeses of the Beatitudes", p. 144-5. Pinckaers se muestra de acuerdo: "Los platonistas fomentan el triunfo sobre los placeres sensuales para poder alcanzar el gozo causado por la contemplación de las Ideas", "Reappropriating...", op. cit., p. 275. Por su parte, san Agustín hace una lectura positiva de la visión de los platonistas con respecto a la moralidad de las pasiones en De civ. Dei, libro IX, cap. 4 (CCSL 47, 251).

${ }^{37}$ Buenaventura forja su posición en III Sent., d. 33, a. 1, q. 3 (ed. Quaracchi, 715-8). La disputa con el Aquinate en torno a ello se encuentra bien documentada por M. D. Chenu en "Les passions vertueuses. L'anthropologie de saint Thomas", p. 11-18; e idem, "Body and Body Politic in the Creation Spirituality of Thomas Aquinas", p. 214-32. 
sólo puede surgir de un acto de la voluntad, y no también de nuestro apetito inferior, dado que sostienen que únicamente el libre albedrío añade valor moral a nuestras acciones. ${ }^{38}$

En resumen, Buenaventura y Escoto conciben la relación entre las potencias superiores e inferiores del alma más en términos de sumisión impuesta: la razón y la voluntad simplemente imponen su poder sobre el apetito sensitivo. La virtud no transforma las emociones en movimientos virtuosamente orientados; sólo 'doma' las pasiones mediante lo que Buenaventura denomina una forzada 'sumisión a la razón' (optemperat rationi). ${ }^{39}$ Esta sumisión a la razón proviene de los poderes racionales, tanto de lo superior como de lo exterior.

También se puede sumar a Descartes, quien por otro lado ridiculiza los escritos de sus predecesores sobre la emoción, como promotor de la visión que truncaría cualquier sinergia o comunicación real entre la dimensión inferior de la vida humana y del juicio razonado. ${ }^{40}$ Inspi-

${ }^{38}$ Escoto resume su posición cuando escribe, en $O p$. $O x$., libro III, d. 33, q. 1: "las virtudes morales no deben considerarse presentes principalmente en la parte sensitiva del alma [...] Porque la voluntad [exclusivamente se relaciona con el actuar] correcta e incorrectamente [...] Y la única necesidad de considerar a las virtudes como facultades reside en que las facultades, que de suyo son capaces de actuar correcta e incorrectamente, puedan regirse por aquéllas". Para estudios sobre la enseñanza de Escoto sobre las pasiones, cfr. Alan R. Perreiah, "Scotus on Human Emotions", Franciscan Studies, 1998, 56, p. 325-45; y F. de J. Chauvet, "Las ideas filosóficas de J. Duns Escoto sobre las pasiones", Estudios Franciscanos, 1936, 48, p. 244-65. Para una presentación general del pensamiento de Escoto, cfr. Allan B. Wolter, Duns Scotus on the Will and Morality, 1986, Washington, D. C., Catholic University of America Press; Tobias Hoffmann, "The Distinction between Nature and Will in Duns Scotus", Archives d'Histoire Doctrinale et Littéraire du Moyen Age, 1999, 66, p. 189-224; y, para la virtud de la prudencia en particular, Mary Elizabeth Ingham, "Practical Wisdom: Scotus's Presentation of Prudence", en John Duns Scotus: Metaphysics and Ethics, 1996, Leiden, E. J. Brill, L. Honnefelder, et al (eds.), p. 551-71.

${ }^{39}$ Buenaventura, III Sent., d. 33, a. 1, q. 3, ad 1 (ed. Quar., 717). La posición de Escoto, como se señaló en la nota anterior, coincide en mucho con la de Buenaventura: "y la única necesidad de considerar a las virtudes como facultades reside en que las facultades, que de suyo son capaces de actuar correcta e incorrectamente, puedan regirse por aquéllas". $O p$. $O x .$, Bk. III, d. 33, q. 1.

${ }^{40}$ En su The Passions of the Soul, parte. 1, art. 1 Descartes escribe: "Los defectos de las ciencias que hemos heredado de los antiguos en ninguna parte son más aparentes que en sus escritos sobre las pasiones [...] Las enseñanzas de los antiguos acerca de las pasiones 
rado por su antropología dualista, Descartes confina a las pasiones exclusivamente al reino del cuerpo. Y dado que el cuerpo está unido superficialmente al alma, las pasiones no guardan una relación intrínseca con el verdadero bien humano, lo concerniente al alma. ${ }^{41} \mathrm{Su}$ visión se aproxima a la posición de Buenaventura y del doctor sutil en que Descartes asigna a la virtud la tarea de 'reinar' y 'domesticar' las emociones, casi contra su voluntad, o al menos, a pesar de la inclinación propia del apetito sensitivo.

No muy alejada de la posición de Buenaventura y Escoto -0 , para el caso, del estoicismo-, se encuentra la visión del influyente filósofo germano moderno, Immanuel Kant. Evidentemente, este pensador construye su sistema moral desde un rechazo anti-realista de la naturaleza objetiva del ser humano, que le sirve como base para su teoría moral;

son tan magras, y en su mayor parte tan poco plausibles (si peu croyable), que no puedo esperar acercarme a la verdad, salvo partiendo de los caminos que ellos siguieron”, en The Philosophical Writings of Descartes, 1985, Cambridge, Cambridge University Press, trad. de Robert Stoothoff, vol. 1, p. 328. Descartes, quien por su parte brinda escasa atención a la moralidad de las pasiones en su prolijo trabajo, puesto que separa las pasiones de la acción virtuosa, tampoco leyó al Aquinate o, sencillamente, falla al otorgar a santo Tomás lo que merece (o, dado el caso, también a Aristóteles). Pinckaers ofrece una detallada comparación entre la enseñanza de Descartes sobre las pasiones y la de santo Tomás en "Reappropriating Aquinas's Account of the Passions”, p. 279-82.

${ }^{41}$ Descartes mismo escribe: "Sólo al cuerpo podemos atribuir todo aquello que podemos observar como opuesto a la razón [...] Debe observarse [entonces] que [las pasiones] están todas ordenadas por naturaleza para que estén relacionadas con el cuerpo, y para pertenecer al alma sólo en cuanto ésta esté vinculada al cuerpo", The Passions of the Soul, parte 1, art. 47, y parte 2, art. 137 (ed. R. Stoothoff, p. 346 y p. 376). Esto lo lleva a aislar las pasiones del trabajo de la virtud en la parte 2, art. 148 (ibid., p. 382): "Puesto que, si alguno vive de tal forma [...] de lo que llamo aquí 'búsqueda de la virtud', recibirá de ello tal satisfacción que tiene el poder para hacerlo una persona feliz, tanto que los más violentos asaltos de la pasión nunca tendrán poder suficiente para perturbar la tranquilidad de su alma." También, en parte 3, art. 212 (ibid., p. 404), escribe: "el uso principal de la sabiduría descansa en enseñarnos a ser amos de nuestras pasiones y a controlarlas con tal maestría que los males que causan resulten suficientemente soportables". Para un interesante estudio que critica el radical dualismo de Descartes y la forma en que éste impacta sobre su enseñanza en torno a las pasiones, cfr. Antonio Damasio, Descartes' Error: Emotion, Reason, and the Human Brain, 1994, New York, Putnam. Aquí, Damasio muestra cómo el razonar práctico y los estados afectivos resultan severamente debilitados por el daño que sufren las áreas del cerebro responsables de la afectividad. 
es decir, su pensamiento moral presupone la negación de cualquier conocimiento objetivo del ser. Esto lleva a Kant (de quien no podemos descartar la supeditación a la influencia del nominalismo, vía Lutero) a desechar nuestras inclinaciones y movimientos sensibles, incluidas las emociones (parte integral de una 'naturaleza humana objetiva'), en la búsqueda de la excelencia moral. Insiste en que la única cosa buena intrínsecamente, y el único sujeto de la buena acción moral, es la buena voluntad. ${ }^{42}$ La razón humana -famosa aseveración de Kant, llena de reminiscencias estoicas-, por tanto, debe emitir sus mandatos “con desprecio y desdén” por las 'impetuosas' inclinaciones naturales (incluidas las emociones). Éstas nada representan salvo "el poderoso contrapeso del deber moral", 43

42 "El valor moral [...] no puede descansar en ningún lado salvo en el principio de la voluntad", Immanuel Kant, Groundwork of the Metaphysics of Morals, 1998, Cambridge, Cambridge University Press, ed. y trad. de Mary Gregor, sección 1, p. 13; cursivas del autor. Deberíamos sorprendernos por cuán similar es esta aseveración comparada con la citada de Escoto, Op. Ox., libro III, d. 33, q. 1: "las virtudes morales no deben considerarse presentes principalmente en la parte sensitiva del alma [...] Porque la voluntad [exclusivamente se relaciona con el actuar] correcta e incorrectamente". Para estar seguros, en la misma sección del Groundwork, Kant atribuye "genuino valor moral" solamente a una obra bien hecha "no por inclinación sino por deber" (p. 12), ya que "una acción derivada del deber deja por completo de lado la influencia de la inclinación" (en donde inclinación incluiría los movimientos de la sensibilidad, las emociones, p. 13); sostiene que honorable es sólo la clase de amor que "descansa en la voluntad y no en la propensión al sentimiento (Empfindung)", p. 13; y asevera que el cimiento para el deber proviene del hecho de que "nada queda a la voluntad que pueda determinarla excepto, objetivamente, la ley, y, subjetivamente, el respeto puro por esta ley práctica [cursivas suyas]; y, así, la máxima de obedecer tal ley incluso cuando ésta infringe todas mis inclinaciones", p. 13-4. Para un estudio conciso e iluminador sobre la filosofía moral de Kant, cfr. Robert Sokolowski, Moral Action: A Phenomenological Study, 1985, Bloomington, Indiana University Press, Apéndice D, “Kant”, p. 215-20.

${ }^{43}$ Kant escribe en Groundwork of the Metaphysics of Morals (op. cit., p. 17): "El ser humano siente dentro de sí mismo un poderoso contrapeso a todos los mandamientos del deber [...] el contrapeso de sus necesidades y satisfacciones [...] Ahora, la razón obedece sus preceptos incesantemente, sin que por ello prometa nada a las inclinaciones, y así, como debe ser, con desprecio y desdén para tales demandas [de las inclinaciones], que son tan impetuosas y, además, tan aparentemente justas (y que se niegan a ser neutralizadas por ningún mandato)." Comentando este elemento de pensamiento de Kant, R. Sokolowski (Moral Action, p. 215-6) observa: "La buena inclinación es contrastada por la bondad moral de la voluntad [...] La razón, por tanto, legisla para sí misma; no tienen sus normas dispuestas 
Entonces, cuando para santo Tomás lo que hemos de hacer debería incluir a nuestras pasiones y deseos, y cuando la vida moral debería ser primordialmente una vida de alegría, para Kant el deber moral precisa que nos alejemos de nuestras emociones y deseos. Éstos tienen, o al menos deberían tener, poco o nada que ver con nuestras obligaciones morales. Debemos hacer lo que tenemos a pesar de nuestras pasiones y deseos. $^{44}$

En cuanto al extremo filosófico que pone en manos de las pasiones, como tales, a los reinos de la conducta moral, debe mencionarse en primer lugar al epicureísmo. De acuerdo con esta antigua filosofía moral, la vida buena, la vida de excelencia moral, consiste en la búsqueda del placer y en evitar el dolor; la meta epicúrea es lograr una vida libre de toda perturbación (ataraxia).$^{45}$ Como comenta Pinckaers: "los epicúreos sitúan la felicidad en el nivel de las emociones". ${ }^{46}$

Un paralelo cercano a la visión epicureísta surgirá más tarde en el pensamiento moral del filósofo escocés anti-racionalista, David Hume. La filosofía moral de Hume, como el estoicismo, oscurece cualquier distinción real entre los actos de la voluntad y los movimientos irracionales inferiores de la sensibilidad. De cualquier forma, cuando en el estoicismo este oscurecimiento lleva a una actitud de menosprecio por la emoción, actitud compartida por Kant, en Hume llega a la conclu-

para ella por naturaleza [...] La filosofía moral de Kant [entonces] asume un conflicto entre la razón práctica o la voluntad, por un lado, y la necesidad, inclinación, deseo, aversión o sensibilidad, por el otro."

${ }^{44}$ Sin exageración, Richard Taylor (Good and Evil: A New Direction, 1970, New York, Macmillan, p. 103-15) describe el sistema moral de Kant con precisión cuando escribe que "para ser genuinamente moral [para Kant], un hombre debe alejarse de sus inclinaciones como ser que ama, debe apartar los impulsos simpatéticos de su corazón, debe desdeñar cualquier fruto de sus esfuerzos, debe pensar hasta el final en sus sentimientos, necesidades y deseos, sean suyos o de su prójimo y, tal vez, debe detestar lo que tiene que hacer, pero debe hacerlo de cualquier manera -sólo por respeto a la ley".

${ }^{45}$ Escribe el materialista Epicuro, fundador del epicureismo, quien vivió del 341 al 270 a. de C.: "el placer es el punto de partida y meta para el vivir de manera feliz", Letter to Menoeceus, en Hellenistic Philosophy: Introductory Readings, 1988, Indianapolis, Hacket, trad. y ed. Brad Inwood y P. Gerson, p. 24.

${ }^{46}$ Pinckaers, "Reappropriating Aquinas's Account of the Passions", p. 275. 
sión opuesta. Para él, la virtud se identifica con los movimientos de la pasión como tal. Decir placer es decir virtud, y decir dolor es decir vicio. ${ }^{47}$ En resumen, para Hume los juicios morales no son otra cosa que expresiones del sentimiento. Así, no debemos sorprendernos al leer que asevera, más bien de forma provocativa: "la razón es, y sólo puede ser, la esclava de las pasiones, y no puede pretender jamás otra función que servirlas y obedecerlas". ${ }^{48}$

Cercanamente relacionada con la postura de Hume se encuentra la de su predecesor, el filósofo del siglo XVII, Thomas Hobbes, quien define nuestra vida interna en términos por completo mecanicistas, o en términos de materia en movimiento. Los estados internos de la persona humana no consisten más que en percepciones sensoriales de objetos materiales, que originan sensaciones agradables o desagradables; éstas, a su vez, terminan en deseos o aversiones (temores), respectivamente. ${ }^{49}$ De esta forma, como con Hume, el sistema moral

${ }^{47}$ En A Treatise of Human Nature, libro III, parte 3, secc. 1 (1960, Oxford, Clarendon Press, p. 574), Hume afirma: "El origen fundamental del principio actuante de la mente humana es el placer o el dolor [...] Los más inmediatos efectos del placer y del dolor son los propensos o adversos movimientos de la mente, los cuales se diversifican en volición, deseo y aversión, pena y alegría, esperanza y temor; de acuerdo con su dolor o placer cambia su situación”, cursivas mías. Así, Hume continúa con las rígidas implicaciones morales de esta postura (ibid., p. 574-5): "las distinciones morales [entonces] dependen enteramente de ciertos sentimientos particulares de placer y dolor; y ello, sea cual fuere la cualidad mental dentro de nosotros o de otros, nos proporciona una satisfacción [i. e. placer], por supuesto virtuosa; como cualquier cosa de esta naturaleza, que nos produce inquietud $[i . e$. dolor], es viciosa". Lo repite poco después (ibid., p. 590): "cada pasión u operación de la mente tiene un sentimiento particular, el cual puede ser ya agradable, ya desagradable. El primero es virtuoso; vicioso, el segundo". Para abundar en ello, cfr. Donald MacNabb, "David Hume", en Encyclopedia of Philosophy, 1972, New York, Macmillan, vol. 4, p. 85-8.

${ }^{48}$ David Hume, A Treatise of Human Nature, libro. II, parte 3, secc. 3, 415. Hume establece después: "Bien y mal morales son ciertamente distinguidos por nuestros sentimientos, no por nuestra razón", libro III, parte 3, secc. 1, p. 589, cursivas suyas. De conformidad con lo anterior, Judith Barad observa: "David Hume [...] sostiene que la elección de los valores fundamentales siempre se lleva a cabo por la parte emocional de nuestra naturaleza", "Aquinas on the Role of Emotion in Moral Judgment and Activity", Thomist, 1991, 55, p. 371.

49 "La vida raras veces es otra cosa que movimiento, y no puede darse sin deseo y sin temor, como no puede existir sin sensaciones", Thomas Hobbes, Leviathan (publicado por vez primera en 1651), 1968, Middlesex-Baltimore, Penguin Books, reimpreso en 1981, ed. C. B. Macpherson, parte 1, cap. 6, 130 . 
de Hobbes se basa completamente en nuestras pasiones, en nuestros gustos y disgustos afectivos. La 'vida buena', la vida moral, consiste en la simple satisfacción de nuestros propios deseos. Como los animales, somos criaturas egoístas por completo, auto-interesadas, para quienes 'bien' es significativo sólo en relación con objetos materiales. 'Bien' sólo designa objetos de nuestros deseos o aversiones, no ciertos bienes primordiales, comunes y compartidos por todos los seres humanos. ${ }^{50}$ Entonces, si para santo Tomás nuestras emociones señalan una dimensión menor de la vida interior del ser humano, para Hobbes son parte integral de la única dimensión de la vida humana, dado que define al hombre simplemente como una máquina, definición que cierto autor moderno proclama que establece "un gran paso hacia delante en el pensamiento" $(i !) .^{51}$

Un equivalente de la visión hume-hobbesiana resurgiría más tarde con el utilitarismo de Jeremy Bentham y John Stuart Mill. Para estos filósofos, el deber moral yace en estricta correspondencia con las inclinaciones sensibles al placer. Lo que uno ha de hacer es aquello

${ }^{50}$ Como afirma Hobbes en Leviathan, parte 1, cap. 6 (ed. Macpherson, 120-2): "Pero estas palabras, de Bueno, Malo y Despreciable siempre se usan en relación con la persona que las utiliza. No son siempre y absolutamente tales, ni ninguna regla del bien y del mal puede tomarse de la naturaleza de los objetos mismos, sino del individuo [...] Por tanto, placer (o deleite) es la apariencia o sensación de lo bueno; y molestia o desagrado, la apariencia o sensación de lo malo. De aquí que todo deseo, apetito y amor está acompañado de cierto deleite más o menos intenso; y todo lo odiado y la aversión, se acompañan con desagrado y ofensa, mayor o menor", cursivas suyas. La identificación de Hobbes del bien con el placer y del mal con el dolor, o el oscurecimiento de la emoción con virtud y vicio, se encuentra en Leviathan, parte 1, cap. 6 (ed. Macpherson, 122-7); aquí enlista lo que denomina las variadas clases de placeres (o deleites) y dolores (o desagrados): apetito, deseo, amor, aversión, odio, alegría, pena, dolor, esperanza, desesperación, temor, valor, cólera, confianza, desconfianza, indignación, benevolencia, bondad natural, codicia, ambición, pusilanimidad, magnanimidad, valor, liberalidad, miseria, amabilidad, deseo, lujuria, celos, afán de venganza, curiosidad, religión, superstición, terror pánico, admiración, gloria, vanagloria, desaliento, entusiasmo repentino, risa, desaliento repentino, llanto, vergüenza, rubor, impudicia, lástima, crueldad, emulación, envidia, deliberación.

${ }^{51}$ La proclamación de que la visión mecanicista del ser humano de Hobbes marca un avance significativo en el pensamiento humano proviene de R. S. Peters, "Thomas Hobbes", en The Encyclopedia of Philosophy, 1972, New York, Macmillan, ed. Paul Edwards, vol. 4, p. 39. 
acorde con el placer mayor y más duradero. Para ellos, lo anterior se debe a que el placer señala el único bien intrínseco (y el dolor el único mal intrínseco): la felicidad, como Mill establece con severidad, consiste en "el placer y en la liberación del dolor". ${ }^{52} \mathrm{El}$ disfrute del mayor número de bienes materiales por el mayor número de personas constituye la meta del utilitarismo británico.

\section{Conclusión}

Fungiendo como contrapeso de una poderosa voz dentro de la tradición filosófica, santo Tomás sonríe amablemente al papel de la emoción en la vida moral. De ninguna manera nuestras pasiones y deseos, que impactan significativamente en la forma en que pensamos y elegimos, deben ser excluidas de la búsqueda humana por la excelencia moral. No importa su frecuente e inquietante interferencia en la vida moral: están destinadas a desarrollar una parte integral en nuestra lucha por el Bien primero y por la felicidad primordial. El Aquinate incluso va más lejos al insistir en que la virtud moral puede curar la desordenada naturaleza de las pasiones, al grado de que el individuo virtuoso no solamente no es perturbado por sus pasiones, si no que, de hecho, es ayudado por ellas para vivir virtuosamente. Por medio del crecimiento en la virtud moral, las pasiones consiguen la habilidad de inclinarnos hacia nuestro bien más alto. Pueden ayudar a esculpir nuestras vidas como obras de excelencia moral.

En términos prácticos, lo anterior significa que, mientras más virtuoso se vuelve uno, más puede confiar en sus reacciones emocionales que produce hacia las personas y hacia las situaciones en general; y tanto menos se habrá de luchar contra los impulsos irracionales inferiores. Existe, pues, una gran probabilidad de que nuestras emociones nos

52 John Stuart Mill, Utilitarianism, cap. 2, Collected Works of John Stuart Mill, 1963, Toronto, University of Toronto Press, vol. X, p. 210. Cfr. Jeremy Bentham, Introduction to the Principles of Morals and Legislation, 1970, London, Athlone Press, I, 1. 
inclinen hacia lo que es moralmente bueno para nosotros. En verdad, siempre queda la posibilidad de que nuestras emociones nos alejen del bien racional; pero para el individuo virtuoso, para quien la virtud de la prudencia salvaguarda de juicios erróneos sobre los movimientos particulares de la emoción, existe una mayor probabilidad de que sus pasiones lo conduzcan hacia bienes materiales creados que gozan, de manera auténtica, del bien de la razón. Existe, pues, mayor posibilidad de que ayuden a dicha persona a alcanzar su propio florecimiento humano. Esto, en todo caso, es lo que nos permite concluir la doctrina de 'notable genialidad' de santo Tomás, en torno al papel de las pasiones en la vida moral. 
La reproducción total o parcial de este artículo se podrá hacer si el ITAM otorga la autorización previamente por escrito. 